Jurnal Pembangunan Pendidikan: Fondasi dan Aplikasi

Volume 3, No 2, Desember 2015 (166-171)

Online: http://journal.uny.ac.id/index.php/jppfa

\title{
MATAHARI YANG TERLUPAKAN: PENDIDIKAN KARAKTER DALAM PEMBELAJARAN BAHASA DAN SASTRA INDONESIA DI SEKOLAH
}

\author{
Sudaryanto \\ Program Studi Pendidikan Bahasa dan Sastra Indonesia FKIP Universitas Ahmad Dahlan \\ sudaryanto82@yahoo.com
}

\begin{abstract}
Abstrak
Penumbuhan sikap-sikap atau karakter-karakter positif dan nilai-nilai luhur pada diri siswa dapat melalui proses pembelajaran di kelas, salah satunya ialah melalui pembelajaran bahasa dan sastra Indonesia. Selain dididik untuk memiliki karakter membaca dan kreatif, siswa dapat pula dididik untuk memiliki karakter jujur, sopan santun, empati pada sesama atau teman sebaya, dan menghormati orang tua dan gurunya. Para siswa di sekolah akan senang membaca dan mengarang karya sastra apabila para gurunya telah senang membaca dan mengarang karya sastra pula. Dalam hal ini, forum para guru (Musyawarah Guru Mata Pelajaran) dapat dimanfaatkan untuk forum diskusi antarguru dalam mengapresiasi dan berkreasi karya sastra, serta dukungan dari pihak sekolah terhadap ketersediaan bahan bacaan karya sastra yang lengkap di perpustakaan sekolah.

Kata kunci:
\end{abstract}

\section{FORGOTTEN SUN: \\ CHARACTER EDUCATION IN INDONESIAN LANGUAGE AND LITERATURE INSTRUCTION AT SCHOOL}

\author{
Sudaryanto \\ Program Studi Pendidikan Bahasa dan Sastra Indonesia FKIP Universitas Ahmad Dahlan \\ sudaryanto82@yahoo.com
}

Abstract

Inculcating positive attitudes or positive characters and high values in students can be through teaching processes in the classroom, one of which is through teaching Indonesian language and literature. In addition to being taught to have reading and creative character, students can also be taught to have character of honesty, good manner, empathy for others or peers, and respect to parents and teachers. The students at the school will be happy to read and compose literary works when their teachers have enjoyed reading and composing literary works as well. In this case, the teachers' forum (Musyawarah Guru Mata Pelajaran/MGMP) can be used as teachers' discussion forum in appreciating and creating literary work, as well as support from the school to the availability of a complete reading of literary work in the school library.

Keywords: 



\section{PENDAHULUAN}

Pada 1998 atau tepatnya 16 tahun silam, Taufiq Ismail mengadakan survei tentang pengajaran sastra secara deskriptif-kuantitatif. Survei itu sendiri pada hakikatnya ingin menjawab satu pertanyaan besar yang dirumuskannya menjadi "Benarkah Kini Bangsa Kita Telah Rabun Membaca dan Lumpuh Menulis?". Kemudian, Taufiq merumuskan tiga buah pertanyaan dasar, yaitu: (1) berapa buah buku sastra yang wajib dibaca selama 34 tahun bersekolah di SMU; (2) berapakah jumlah jam bimbingan mengarang diberikan selama 3-4 tahun, dan; (3) serba-serbi pengajaran apresiasi sastra.

Dalam survei yang dilakukan oleh Taufiq, yang dijadikan responden adalah para tamatan SMU di 13 negara. Melalui teknik wawancara, baik langsung maupun tak langsung (melalui surat), informasi dikumpulkan. Berikut ini adalah daftar tamatan sekolah yang diwawancarai oleh Taufiq (via Sayuti, 2005) yang disajikan pada Tabel 1 .

Tabel 1. Jenjang Pendidikan Responden

\begin{tabular}{rlc}
\hline No & Tamatan & tahun \\
\hline 1 & SMU Stamford College, Singapura & 1983 \\
2 & SMU Kolej Melayu Kuala & 1980 \\
& Kangsar, Perak, Malaysia & \\
3 & SMU Narathiwat, Thailand & 1991 \\
4 & SMU Sekolah Menengah Melayu & 1969 \\
& Pertama, Brunei & \\
5 & SMU Urawa, Jepang & 1972 \\
6 & SMU Canterbury, Ottawa, Kanada & 1994 \\
7 & SMU Forest Hills, New York, A.S. & 1989 \\
8 & SMU Gymnasium Wanne, Eickel, & 1975 \\
& Jerman Barat \\
9 & SMU Internasional, Jenewa, Swiss & 1994 \\
10 & SMU Ufa, Sovyet, Rusia & 1980 \\
11 & SMU Ecole Saint, Martin de & 1970 \\
& France, Pontoise, Prancis & \\
12 & SMU Gemeentelijk Gymnasium & 1971 \\
& Middleburg, Belanda & \\
13 & AMS Yogya, Hindia Belanda & 1942 \\
\hline
\end{tabular}

Sebagai hasil jawaban pertanyaan awal, Taufiq pun menyusun daftar berikut ini yang diberikan tajuk "Daftar Jumlah Buku Sastra Wajib Dibaca Selama di SMU, yang Tercantum di Kurikulum, Disediakan di Perpustakaan Sekolah, Dijadikan Subjek Penulisan Siswa, dan Diujikan di Kelas".
Tabel 2. Daftar Jumlah Buku Sastra Wajib Dibaca Selama di SMU

\begin{tabular}{llcl}
\hline No & Sekolah & $\begin{array}{c}\text { Jumlah } \\
\text { Buku }\end{array}$ & Tahun* \\
\hline 1 & SMU Thailand Selatan & 5 judul & 1991 \\
2 & SMU Singapura & 6 judul & 1983 \\
3 & SMU Malaysia & 6 judul & 1980 \\
4 & SMU Brunei Darussalam & 7 judul & 1969 \\
5 & SMU Sovyet Rusia & 12 judul & $1980-$-an \\
6 & SMU Kanada & 13 judul & 1994 \\
7 & SMU Jepang & 15 judul & 1972 \\
8 & SMU Internasional Swiss & 15 judul & 1994 \\
9 & SMU Jerman Barat & 22 judul & 1975 \\
10 & SMU Prancis & 20-30 judul & 1970 \\
11 & SMU Belanda & 30 judul & 1971 \\
12 & SMU Amerika Serikat & 32 judul & 1989 \\
13 & SMU Hindia Belanda & 25 judul & 1942 \\
14 & SMU Indonesia & 0 judul & - \\
\hline
\end{tabular}

Keterangan : *) Tahun tamat responden di SMU bersangkutan. Jumlah buku berlaku untuk masa selama sekolah, dan secara khusus untuk SMU tersebut, serta tidak berlaku secara nasional

Dari surveinya tersebut, Taufiq mencatat beberapa temuan yang bersinggungan dengan pembelajaran bahasa dan sastra di sekolah. Dari sekian temuan survei Taufiq itu, penulis hanya mengambil dua buah, yaitu kegiatan membaca dan bimbingan mengarang di kelas. Keduanya dipilih karena merupakan jantung dari denyut keberhasilan pembelajaran bahasa dan sastra di sekolah. Kemudian, perihal kegiatan membaca dan bimbingan mengarang dikaitkan dengan pendidikan karakter; sebuah wacana yang kini banyak diperbincangkan di dunia pendidikan di Tanah Air.

\section{Rabun Membaca Sastra: Beberapa Problematika dan Pemecahannya}

Berdasarkan hasil survei Taufiq Ismail di atas, siswa SMU di Indonesia bukan berarti tidak mengenal buku sastra. Para siswa SMU tahu nama pengarang, judul novel atau puisi, jalan cerita, hingga riwayat pengarang. Mereka tahu hal-hal itu karena membaca sinopsis buku atau ensiklopedia sastra Indonesia. Namun, menurut Taufiq, para siswa itu tidak mengalami kenikmatan membaca buku sastra secara utuh, karena antara lain, tidak ditugaskan oleh guru Bahasa Indonesia dan terutama tidak disediakan di perpustakaan sekolah.

Dalam kondisi demikian, wajarlah jika siswa kita mengalami kondisi apa yang Volume 4, Nomor 2, Desember 2016 
disebut oleh Taufiq Ismail sebagai "rabun membaca". Di sekolah kita, SMP dan SMU, sangat langka dijumpai potret para siswa asyik membaca buku di berbagai tempat, seperti di perpustakaan, di taman sekolah, di depan kelas, dan sebagainya. Alih-alih buku sastra yang dipegangnya, justru mereka lebih bangga menenteng handphone, gadget, i-pad, serta mengakses Facebook, Twitter, dan Skype. Bagi mereka, mungkin menenteng gadget lebih bergengsi ketimbang novel atau cerpen.

Di samping itu, mengapa para siswa kita kurang gemar membaca karya sastra ialah karena para gurunya tidak memberikan teladan yang baik. Tak banyak guru Bahasa Indonesia kita yang senang membaca karya sastra, baik karya lama maupun karya baru. Novel-novel karya Mochtar Lubis, Pramoedya Ananta Toer, dan AA Navis amat jarang dibaca oleh para guru. Begitu pula kumpulan cerpen Hamsad Rangkuti, Seno Gumira Ajidarma, hingga Agus Noor, serta kumpulan puisi Dorothea Rosa Herliany, Soni Farid Maulana, hingga Joko Pinurbo.

Ketidaksenangan guru Bahasa Indonesia membaca karya sastra disebabkan oleh banyak faktor, antara lain, mahalnya harga buku sastra, minimnya informasi buku sastra terbaru, hingga rendahnya minat baca buku sastra. Hemat saya, dua faktor yang disebut di awal relatif mudah diatasi dengan memanfaatkan keberadaan forum yang bernama $\mathrm{Mu}-$ syawarah Guru Mata Pelajaran (MGMP). Melalui MGMP, para guru Bahasa Indonesia dapat saling bertukar-pinjam buku sastra, serta saling memberikan informasi tentang buku sastra terbaru.

Sebagai gambaran, bisa dibayangkan jika seluruh anggota MGMP Bahasa Indonesia total 20 orang, dan semuanya membeli satu buku sastra terbaru yang berbeda-beda. Ada novel, kumpulan puisi, kumpulan cerpen, hingga kumpulan drama. Lantas, 20 orang guru itu dengan sistem arisan mendapatkan kesempatan untuk membaca buku sastra yang berbeda-beda. Berarti, 20 orang guru Bahasa Indonesia tadi telah berhasil meningkatkan minat bacanya, sekaligus koleganya secara bersama-sama. Saya kira, strategi seperti ini perlu diujicobakan agar semua guru semakin akrab dengan karya sastra.

Strategi tersebut dapat dilakukan di ruang kelas. Para siswa disuruh membawa buku sastra yang berbeda-beda. Ada novel, kumpulan puisi, kumpulan cerpen, dan kumpulan drama. Mereka dapat saling bertukarpinjam buku sastra tersebut. Penulis yakin, melalui strategi bertukar-pinjam buku sastra itu, para siswa dapat juga meningkatkan minat baca buku sastra yang awalnya rendah. Bila minat baca karya sastra siswa meningkat (diikuti minat baca buku non-sastra), berarti pula karakter membaca telah tumbuh pada diri siswa kita.

Sementara itu, persoalan langkanya buku sastra di perpustakaan sekolah dapat disiasati dengan beragam cara, salah satunya ialah menggerakkan para alumni untuk menyumbang buku sastra bagi perpustakaan sekolah. Sekali lagi, Anda bisa bayangkan betapa semua alumni melakukan gerakan sumbang buku sastra bagi sekolahnya masingmasing, kelak terjadi peningkatan jumlah buku sastra di perpustakaan sekolah. Jika jumlah satu angkatan alumni sekitar 150-180 orang, berarti ada penambahan jumlah buku sastra sebanyak 150-180 buku sastra. Jumlah yang tak sedikit bukan?

Dengan demikian, karakter membaca karya sastra, baik para guru, siswa, maupun alumni dapat ditumbuhkan selama ada keinginan kuat untuk menumbuhkannya, di samping adanya dorongan dan pembiasaan yang perlu juga dilakukan (bdk Puskurbuk Kemendiknas, 2011). Tanpa itu, saya kira penumbuhan karakter membaca karya sastra tidak akan pernah terwujud. Lihatlah masyarakat Jepang yang dalam kesehariannya tak pernah terlepas dari kegiatan membaca! Karakter membaca pada masyarakat Jepang tumbuh seiring dengan tingginya minat baca mereka.

Terkait karya sastra, pendapat Bohlin (2005, p. 27) yang menyatakan bahwa karya sastra memberikan wawasan istimewa tentang moral dalam kehidupan layak disimak. Melalui karya sastra, baik para guru maupun siswa mendapatkan wawasan atau hikmah (dalam bahasa agama Islam) mengenai gambaran perilaku yang baik dan buruk. Misalnya, melalui puisi "Aisyah Adinda Kita" yang ditulisnya pada 1984, Taufiq Ismail hendak mengajak pembaca puisinya, terutama para generasi muda untuk meneguhkan kejujuran, sopan santun, empati pada sesama, dan sebagainya. Perhatikan kutipan puisi tersbut.

Aisyah adinda kita yang sopan dan jelita

Angka SMP dan SMA sembilan rata-rata 
Pandai mengarang dan berorganisasi

Mulai Muharram satu empat nol satu

Memakai jilbab menutup rambutnya

Busana muslimah amat pantasnya

Aisyah adinda kita yang sopan dan jelita

Indeks prestasi tertinggi tiga tahun lamanya

Calon insinyur dan bintang di kampus

Bulan Muharram satu empat nol empat

Tetap berjilbab menutup rambutnya

Busana muslimah amat pantasnya

Aisyah adinda kita

Tidak banyak dia berkata

Dia memberi contoh saja

Ada sepuluh Aisyah berbusana muslimah

Ada seratus Aisyah berbusana muslimah

Ada sejuta Aisyah berbusana muslimah

Aisyah adinda kita

\section{Lumpuh Menulis Sastra: Beberapa Problematika dan Pemecahannya}

Kembali ke hasil survei Taufiq Ismail di atas. Dalam survei yang dilakukannya, Taufiq menyodorkan hasil amatan bimbingan mengarang/menulis yang dilaksanakan di College Melayu Kuala Kangsar (1974-1980), sebuah sekolah gabungan SMP-SMU di Malaysia. Di tingkat SMP, bimbingan mengarang dilaksanakan pada kelas 1, 2, dan 3 Kelas Bahasa serta memiliki target jumlah kata sebanyak 350 kata dan dilaksanakan per minggu. Anda bisa bayangkan, jika siswa rutin mengikuti bimbingan mengarang dalam satu tahun, berarti telah menghasilkan sekitar 48 buah karangan/tulisan.

Kemudian di tingkat SMU, bimbingan mengarang dilaksanakan pada kelas 1 , 2, 3, dan 4, serta memiliki target jumlah kata yang disesuaikan dengan klasifikasi kelas. Misalnya, kelas 1 harus menulis sebanyak 500 kata, kelas 2-500 kata, kelas 3-1000 kata, dan kelas 4-1000 kata. Untuk kelas 1 dan 2, bimbingan mengarang berlaku pada Kelas Bahasa, Kelas Sejarah, Kelas Geografi, dan Kelas Komersial, serta dilakukan sebanyak 4 kali per minggu. Sementara itu, kelas 3 dan 4 bimbingan mengarang berlaku hanya pada Kelas Bahasa dan dilakukan sebanyak 2 kali per minggu.
Dengan gambaran seperti di atas, Anda bisa menebak sekaligus membayangkan bagaimana bimbingan mengarang di College Melayu Kuala Kangsar, khususnya pada periode 1974-1980 berjalan secara intensif dan terukur. Disebut intensif karena jam atau bimbingan mengarang di kelas dilaksanakan secara rutin per minggu; dan disebut terukur karena memiliki target jumlah kata dalam karangan atau tulisan. Dari situlah, sungguh layak kita katakan bahwa pelajaran mengarang di College Melayu Kuala Kangsar, Malaysia, telah berhasil secara kualitas dan kuantitas.

Keberhasilan pelajaran mengarang di College Melayu Kuala Kangsar harus diakui relatif belum dapat ditumbuhkan di SMPSMU Indonesia. Buktinya, pelajaran mengarang hanya dilaksanakan pada Kelas 1 dan 2, sedangkan Kelas 3 sama sekali tidak ada. Para siswa SMU Kelas 3 kita, sebagian besar waktunya dihabiskan untuk berlatih secara massal menyelesaikan butir-butir soal pilihan ganda (multiple choice). Ironisnya lagi, para guru SMP-SMU, termasuk guru Bahasa Indonesia sibuk membuat soal-soal tryout $\mathrm{UN}$, seolah melupakan arti pentingnya pelajaran mengarang.

Setali tiga uang, temuan survei Taufiq lain ialah bahwa di Kanada, Jepang, Swiss, Sovyet Rusia, Jerman Barat, Prancis, Belanda, dan AS, materi tata bahasa tidak lagi diajarkan di SMU. Sembilan tahun di SD dan SMP dipandang sudah sangat cukup sebagai tempat penggemblengan kaidah tata bahasa. Sementara itu, para responden yang merupakan alumni SMU di negara-negara tadi menyatakan, tata bahasa dicek melalui penggunaannya dalam karangan yang harus mereka tulis sebagai tugas. Jadi, tugas mengarang merupakan strategi lain untuk mengecek tata bahasa para siswa.

Berbeda halnya dengan di Indonesia, meskipun sudah di SMU, kemampuan para siswa dalam mengarang ternyata masih rendah. Salah satu buktinya yang bisa dicatat di sini ialah betapa semrawutnya tata bahasa siswa dalam karangan yang mereka hasilkan. Berdasarkan pengalaman pribadi, saya pernah membaca karangan-karangan resensi buku siswa Kelas 3 SMU yang dijadikan sebagai syarat ujian praktik Bahasa Indonesia, hasilnya betul-betul jauh dari yang diharapkan! Selain kesalahan tata tulis dan ejaan, yang pa- 
ling fatal ialah kesalahan logika berpikir dalam karangan mereka.

Hemat penulis, alih-alih mencari kambing hitam dari ketidakmampuan atau kelumpuhan siswa kita dalam mengarang, justru yang perlu kita lakukan saat ini ialah pelajaran Bahasa Indonesia lebih difokuskan pada kegiatan membaca dan mengarang. Di Kelas 1, misalnya, para siswa hanya disibukkan dengan kegiatan membaca dan mengarang puisi dan cerpen. Beragam puisi dan cerpen karya pengarang Indonesia dibaca, diulas, dan dideklamasikan di depan kelas, serta para siswa dididik untuk mengarang kedua genre karya sastra itu secara intensif.

Terkait kegiatan mengarang, penulis sependapat dengan Popp (2005: 92) bahwa melalui kegiatan mengarang, siswa akan dapat mengembangkan apresiasinya terhadap karakteristik jenis-jenis karya dan keterampilan para penulisnya. Sebagai contoh, siswa yang membaca cerpen "Jendela Rara" karya Asma Nadia akan diajak untuk mengalami pengalaman tokoh Rara; seorang gadis yang lugu dan selalu memimpikan sebuah jendela di rumahnya yang berada di kawasan pemulung di Jakarta. Dengan segala tingkahnya, pembaca ikut berempati terhadap apa yang dilakukan oleh Rara.

\section{SIMPULAN}

Berdasarkan paparan tersebut yang terkait dengan pentingnya pendidikan karakter dalam pembelajaran bahasa dan sastra di sekolah, khususnya kegiatan membaca dan menulis. Pertama, para ahli bahasa dan sastra yang terlibat dalam penyusunan kurikulum seharusnya berpikir bahwa dominasi linguistik jangan sampai menghambat pengembangan intelektualitas siswa, dan harus segera diakhiri. Materi tata bahasa Bahasa Indonesia, misalnya, cukup diajarkan pada jenjang SD dan SMP; sementara di jenjang SMU tidak usah lagi.

Di SMU, para siswa cukup disibukkan dengan kegiatan membaca dan mengarang, baik karya fiksi maupun nonfiksi. Misalnya, di Kelas 1 SMU siswa diajarkan untuk membaca dan mengarang puisi dan cerpen. Kemudian di Kelas 2 SMU siswa diajarkan untuk membaca dan mengarang novel dan drama. Selanjutnya, di Kelas 3 SMU siswa diajarkan untuk membaca dan mengarang biografi sastrawan Indonesia. Dengan cara begitu, hemat saya, para siswa akan betulbetul terkondisikan bagaimana mengarang dengan tata bahasa, alur berpikir, hingga daya kreativitas yang optimal.

Kedua, para guru Bahasa Indonesia semestinya memposisikan diri sebagai teladan dalam membaca dan mengarang. Saat ini, tingkat kesejahteraan para guru di Tanah Air kian membaik (berkat adanya tunjangan sertifikasi) maka sepatutnya tiap bulan mereka dapat menyisihkan sedikit uang untuk membeli satu buku sastra yang terbaru, selain juga satu buku populer sesuai dengan hobi mereka. Hal ini perlu dilakukan agar para guru tak selalu berpandangan bahwa harga buku-buku sastra mahal sehingga itu berdampak terhadap minat baca mereka yang rendah.

Hemat penulis, mahal-murahnya harga buku sastra itu relatif, dan hal itu sangat mudah diatasi. Seperti disinggung di atas, para guru dapat memanfaatkan keberadaan forum MGMP sebagai sarana tukar-pinjam buku sastra ataupun buku-buku lainnya. Apabila jumlah pertemuan MGMP dalam setahun 8 kali, berarti tiap-tiap guru yang aktif di MGMP dapat menikmati sebanyak 8 buku sastra terbaru. Nah, coba Anda bayangkan jika MGMP itu berjalan aktif selama dua tahun, tiga tahun, dan seterusnya. Saya yakin akan terjadi peningkatan minat baca pada guruguru kita.

Ketiga, agar pembelajaran bahasa dan sastra di sekolah bergamitan dengan pendidikan karakter, maka kegiatan membaca dan mengarang harus didorong oleh banyak pihak. Pihak sekolah, terutama pimpinan sekolah, dapat melakukan langkah-langkah nyata dalam hal penyediaan buku-buku sastra di perpustakaan sekolah secara memadai. Kemudian yang tak boleh dilupakan, pihak orang tua siswa mestinya mendukung sekaligus mengondisikan budaya membaca dan menulis di rumah masing-masing, seperti membuat perpustakaan pribadi di rumah.

Secara hipotesis, pembentukan karakter seorang anak dimulai dari lingkungan yang terdekat, yaitu keluarga/orang tua, kemudian berturut-turut ialah lingkungan sekolah dan masyarakat. Dalam konteks karakter membaca dan kreatif, saya memiliki dugaan bahwa keduanya perlu ditumbuhkan melalui kegiatan membaca dan menulis secara intensif. Ibarat kata, penulis mengandaikan pendidikan karak- 
ter seperti Matahari yang bersinar sepanjang masa. Meski sinarnya hangat dan sesekali terik bagi kita, tetapi ia kadangkala terlupakan dalam pandangan kita selama ini.

Sebagai penutup, ditukilkan dua bait puisi terakhir dari puisi panjang "Pelajaran Tatabahasa dan Mengarang" (1998, p.172) karya Taufiq Ismail. Kelak, semoga ada inspirasi yang menggugah bagi para guru, siswa, orang tua, pimpinan sekolah, dan masyarakat di Tanah Air dari dua bait puisi di bawah ini.

...

"Anak-anak, bapak bilang tadi

Mengarang itu harus dengan kata-kata sendiri

Tapi tadi tidak ada kosa kata lain sama sekali

Kalian cuma mengulang bolak-balik yang itu-itu juga

Itu kelemahan kalian yang pertama

Dan kelemahan kalian yang kedua

Kalian anemi referensi dan melarat bahan perbandingan

Itu karena malas baca buku apalagi karya sastra."

"Wahai Pak Guru, jangan kami disalahkan apalagi dicerca

Bila kami tak mampu mengembang-kan kosa kata

Selama ini kami 'kan diajar meng-hafal dan menghafal saja

Mana ada dididik mengembangkan logika

Mana ada diajar berargumentasi dengan pendapat berbeda
Dan mengenai masalah membaca buku dan karya sastra

Pak Guru sudah tahu lama sekali

Mata kami rabun novel, rabun cerpen, rabun drama, dan rabun puisi

Tapi mata kami "kan nyalang bila menonton televisi."

\section{DAFTAR PUSTAKA}

Bohlin, K. E. 2005. Teaching character education through literature: awakening the moral imagination in secondary classrooms. London and New York: Routledge Falmer.

Ismail, Taufiq. 1998. Malu (aku) jadi orang Indonesia. Jakarta: Yayasan Ananda.

Popp, Marcia S. 2005. Teaching language and literature in elementary classrooms: a resource book for professional development. Mahwah, New Jersey: Lawrence Erlbaum Associates, Publishers.

Pusat Kurikulum dan Perbukuan. 2011. Pedoman Pelaksanaan Pendidikan Karakter; Berdasarkan Pengalaman di Satuan Pendidikan Rintisan. Jakarta: Kementerian Pendidikan Nasional.

Sayuti, S. A. 2005. Taufiq ismail: karya dan dunianya. Jakarta: Penerbit PT Grasindo. 